\title{
Equatorial wave activity during 2007 over Gadanki, a tropical station
}

\author{
Salaudin Mohammad ${ }^{1, *}$, Gopa Dutta ${ }^{1}$, B Venkateswara RaO ${ }^{2}$ and P Vinay Kumar ${ }^{1}$ \\ ${ }^{1}$ Vignana Bharathi Institute of Technology, Ghatkesar, Hyderabad 501 301, India. \\ ${ }^{2}$ School of Continuing and Distance Education, Jawaharlal Nehru Technological University, \\ Hyderabad 500 085, India. \\ ${ }^{*}$ Corresponding author.e-mail: salauddin.physics@gmail.com
}

ECMWF Re-Analysis (ERA-interim) data of winds for the year 2007 between the pressure levels 1 and $1000 \mathrm{hPa}(0-49 \mathrm{~km})$ have been analyzed for equatorial wave activity over a tropical station Gadanki $\left(13.5^{\circ} \mathrm{N}, 79.2^{\circ} \mathrm{E}\right)$. Available wind observations made by MST radar located at the same site have also been used to investigate the wave activity in the troposphere and lower stratosphere. Waves in the period bands $7-10,12-15$ and 20-30 d are observed. Temporal variability of the wave activity has been investigated by constructing wavelet spectra. The longer period waves show strong seasonal variability with maximum and minimum activities during winter and summer months respectively. Short period activity is more prominent during June--July-August in the tropospheric region. The waves are found to be generated in the troposphere by wind shear and convection. Propagation of the waves to higher altitudes is found to depend strongly on background zonal wind and phase of the quasi-biennial oscillation (QBO). The waves are inhibited to propagate through the negative wind shear zone. Meridional waves might be generated by non-linear wave CISK.

\section{Introduction}

Planetary waves are global scale oscillations and play a significant role in middle atmospheric dynamics. The variabilities observed in tropical wind and temperature fields are, to a large extent, due to some planetary scale equatorial waves (Kelvin and Rossby-gravity waves). These equatorially trapped wave motions are generated in the troposphere and get propagated vertically and zonally through the middle atmosphere with the span of a few days. Upward propagating Kelvin and Rossby-gravity (RG) waves are very important in driving quasi-biennial oscillation (QBO) in the lower atmosphere and semi-annual oscillation (SAO) near the stratopause through wavemean flow interaction (Holton and Lindzen 1972).
Amplitudes of the equatorial waves are expected to decrease with the latitude from the equator with an e-folding latitude of $15^{\circ}$ (Andrews et al. 1987). Quantitative information about the characteristics of these waves are still not adequate enough to assess their contributions in driving $\mathrm{QBO}$ and SAO. The characteristics of the equatorial waves are reported to change as they propagate away from their source region in the troposphere (Liebmann and Hendon 1990). These waves have been observed by radiosonde measurements (Wallace and Kousky 1968; Dhaka et al. 1993; Tsuda et al. 1994; Shimizu and Tsuda 1997; Fujiwara et al. 2001; Holton et al. 2001; Sridharan et al. 2006a, b) and by satellite-based instruments (Canziani and Holton 1998; Mote et al. 2002; Tsai et al. 2004; Ratnam et al. 2004; Randel and Wu

Keywords. Equatorial wave; MST radar; troposphere; stratosphere; middle atmosphere dynamics. 
2005, Alexander et al. 2008; Brahmanandam et al. 2010).

A study of the characteristics of equatorial waves was carried out by Dhaka et al. $(1993,1995)$ over the Indian zone. They analyzed wind data from different Indian stations and obtained prominent oscillations between 5 and $18 \mathrm{~d}$. They observed amplitudes at Hyderabad $\left(17.2^{\circ} \mathrm{N}\right)$ to be maximum which decreased on either side, i.e., over Trivandrum $\left(8.5^{\circ} \mathrm{N}\right)$ and Bhubaneswar $\left(21^{\circ} \mathrm{N}\right)$. Equatorially trapped and convectively coupled waves with $\mathrm{s} \sim 4-7$ are observed to contribute significantly to the momentum budget of the middle atmosphere (Ern et al. 2008). MST radar observations have also been used to estimate momentum flux of equatorial waves in the troposphere and lower stratosphere over Gadanki and the flux is reported to have larger values during equinox than solstices (Sasi et al. 1999; Sasi and Deepa 2001; Krishna Murthy et al. 2002). Sato and Dunkerton (1997) used a new indirect method to estimate momentum flux of gravity and equatorial waves. These planetary scale waves are observed to regulate the dynamics of the middle atmosphere by modulating diurnal tides and gravity waves (Vincent et al. 1998; Wu et al. 1998; Huang et al. 2006, 2010).

Equatorial Kelvin waves are characterized by periods of $\sim 10-20 \mathrm{~d}$ (slow) and $\sim 5-10 \mathrm{~d}$ (fast) and zonal wave numbers 1 and 2 . These waves are found to have enhanced amplitudes around the tropical tropopause with strong static stability and alters the structure of the tropopause, thereby facilitating stratosphere-troposphere exchange (Fujiwara et al. 1998, 2001; Krishna Murthy et al. 2002; Ryu et al. 2008; Flannaghan and Fueglistaler 2011). Low frequency Kelvin waves have vertical wavelengths between 5 and $10 \mathrm{~km}$, whereas high frequency waves are observed to have wavelengths $>10 \mathrm{~km}$ and can be easily resolved by satellite instruments (Salby et al. 1984; Mote et al. 2002). The waves are found to be quasi-stationary near the tropopause. Using global positioning system (GPS) radio occultation (RO) data of temperature, Tsai et al. (2004) reported the evidence of equatorial Kelvin waves in the tropical upper troposphere and lower stratosphere. Their results indicated mixed Kelvin waves of zonal wave number 1 and 2 with period bands $20-30$ and $12.5-14 \mathrm{~d}$. The vertical wavelengths reported by them are 7.6$8.5 \mathrm{~km}$ in 2001 and $4.4-5.8 \mathrm{~km}$ in 2002 near the tropopause. The study of Tsai et al. (2004) was extended by Randel and $\mathrm{Wu}$ (2005). Analyzing GPS radio occultation data, they showed the evidence of Kelvin waves with maximum amplitude near the tropopause $(\sim 17 \mathrm{~km})$ and with vertical wavelengths between 4 and $8 \mathrm{~km}$. They observed close correspondence between Kelvin waves and transient deep convection. Kelvin waves were also found to propagate to lower stratosphere when the easterly phase of QBO oscillations existed and were confined to upper troposphere during its westerly phase.

This paper reports observations of equatorial waves using ERA-interim wind data of the year 2007 for the tropical station Gadanki $\left(13.5^{\circ} \mathrm{N}\right.$, $79.2^{\circ} \mathrm{E}$ ). The horizontal wind data obtained from Gadanki MST radar between February-March and June-October, 2007 have been analyzed in a similar manner to find the seasonality of the waves and their characteristics in the upper troposphere and lower stratosphere. The similarity between the results obtained with radar and ERA data has also been highlighted.

\section{Database}

The high-power MST radar at Gadanki $\left(13.5^{\circ} \mathrm{N}\right.$, $79.2^{\circ} \mathrm{E}$ ) operates at $53 \mathrm{MHz}$ frequency with an average power-aperture product of $7 \times 10^{8} \mathrm{Wm}^{2}$. The peak transmitter power is $2.5 \mathrm{MW}$. It is a coherent pulsed Doppler radar and consists of 1024 crossed three element Yagi-antennas over an area of $130 \mathrm{~m}^{2}$. It measures three-dimensional wind profiles in the troposphere and lower stratosphere between 3.75 and $21 \mathrm{~km}$. A detailed description of the system is given by Rao et al. (1995).

The VHF radar at Gadanki is operated every day in the evening at 17:30 (LT) for $\sim 45-50 \mathrm{~min}$ in six beam directions: North, South, East, West (off-vertical) and ZX, ZY (vertical). The details of the experimental specifications are given in table 1. The averaged daily evening data of radial velocities in six beam directions are used to calculate zonal, meridional and vertical velocities. The horizontal velocities, so obtained are then checked for data continuity. Wind data from 2 February-31 March, 2007 and from 1 June-31 October, 2007 are found to be fairly continuous with a few gaps which are linearly interpolated and used for the present study. Appreciable amplitudes of tidal oscillations

Table 1. Experimental specifications.

\begin{tabular}{ll}
\hline Data base & $\begin{array}{l}\text { Year 2007 (February-March } \\
\text { and June-October) }\end{array}$ \\
Data type & CMO evening data \\
Time gap & $4 \mathrm{~min} 40 \mathrm{sec}$ \\
No. of range bins & 147 \\
No. of FFT points & 512 \\
No. of coherent integrations & 64 \\
No. of incoherent integrations & 1 \\
Inter pulse period & $1000 \mathrm{~ms}$ \\
Pulse width & $16 \mu \mathrm{s}$ \\
No. of beams & $6(\mathrm{E}, \mathrm{W}, \mathrm{N}, \mathrm{S}, \mathrm{ZY}$ and ZX) \\
Beam angle & $10^{\circ}$ \\
\hline
\end{tabular}


over Gadanki have been reported (Sasi et al. 1998; Dutta et al. 2002). Since the radar evening data is collected for $<1 \mathrm{hr}$ everyday, it might deviate from the daily mean winds. The 24-hr tidal amplitudes have been deduced using ERA wind data of each day for the months between February-March and June-October, 2007. The amplitudes and phases of the diurnal oscillation of each day have been used to reconstruct the fluctuations for 17:00 LT (approximate time of evening observations) and removed from the daily fluctuations. The data available for the months of January, April, May, November and December, 2007 are found to have long data gaps which make them unworthy for interpolation.

Since radar data is not available for the complete year (2007) and the altitude region is limited to the lower stratosphere $(20 \mathrm{~km})$, ECMWF Re-Analysis (ERA-interim) data for $13.5^{\circ} \mathrm{N}, 79.5^{\circ} \mathrm{E}$ which is the closest location to Gadanki have been downloaded for the period January-December, 2007. Daily wind data have been obtained by averaging four data points $(00,06,12$ and 18 GMT) available for each day. The horizontal wind data between the pressure levels 1 and $1000 \mathrm{hPa}$, i.e., between 0 and $49 \mathrm{~km}$ have been analyzed for similar long period wave activity and compared with radar observations. The results obtained from ERA and radar data have been compared to find out the similarity.

\section{Background wind system}

The background wind system has profound effect on planetary wave activity and should be analyzed thoroughly. Profiles of monthly averaged zonal and meridional wind velocities (ERA data) are shown in figure $1(\mathrm{a}-\mathrm{b})$. The zonal wind is generally found to be very weak below $5-7 \mathrm{~km}$. Eastward winds are observed in the altitude region between 7 and $\sim 18 \mathrm{~km}$ from January to April which turn into westward winds during May to October. Easterly velocities increase in magnitude with height maximizing at $\sim 15 \mathrm{~km}$. Tropical easterly jets are observed during summer monsoon months (June, July and August) with a maximum mean velocity of $\sim-35 \mathrm{~m} / \mathrm{s}$. The zonal velocities then get reduced and minimum values are observed at $\sim 20$ $\mathrm{km}$. Stratospheric zonal winds show maximum westward values above $30 \mathrm{~km}$ in mid-stratosphere between January and April. The height of maxima slowly reduces to $\sim 26 \mathrm{~km}$ in the months of November and December with smaller amplitudes. Meridional wind profiles (figure 1b) show southerly winds in the troposphere between January and April. The direction of wind changes from southerly to northerly between May and September which again changes sign during October and December. Meridional winds between 20 and 40 $\mathrm{km}$ are weakly positive in April-May and fluctuate
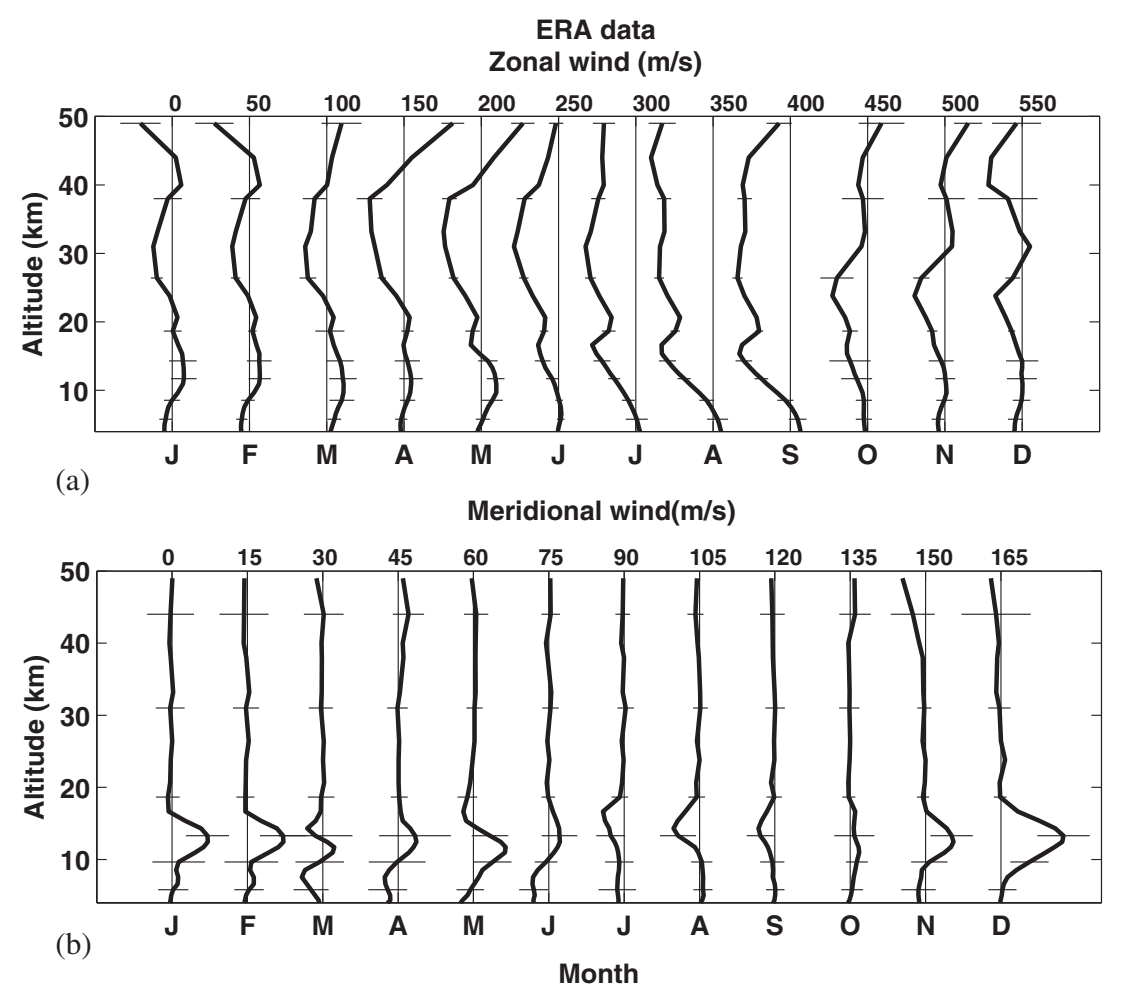

Figure 1. Mean monthly profiles of (a) zonal and (b) meridional winds with standard deviations at a few heights. Zonal and meridional profiles are shifted by $50 \mathrm{~m} / \mathrm{s}$ and $15 \mathrm{~m} / \mathrm{s}$, respectively. 

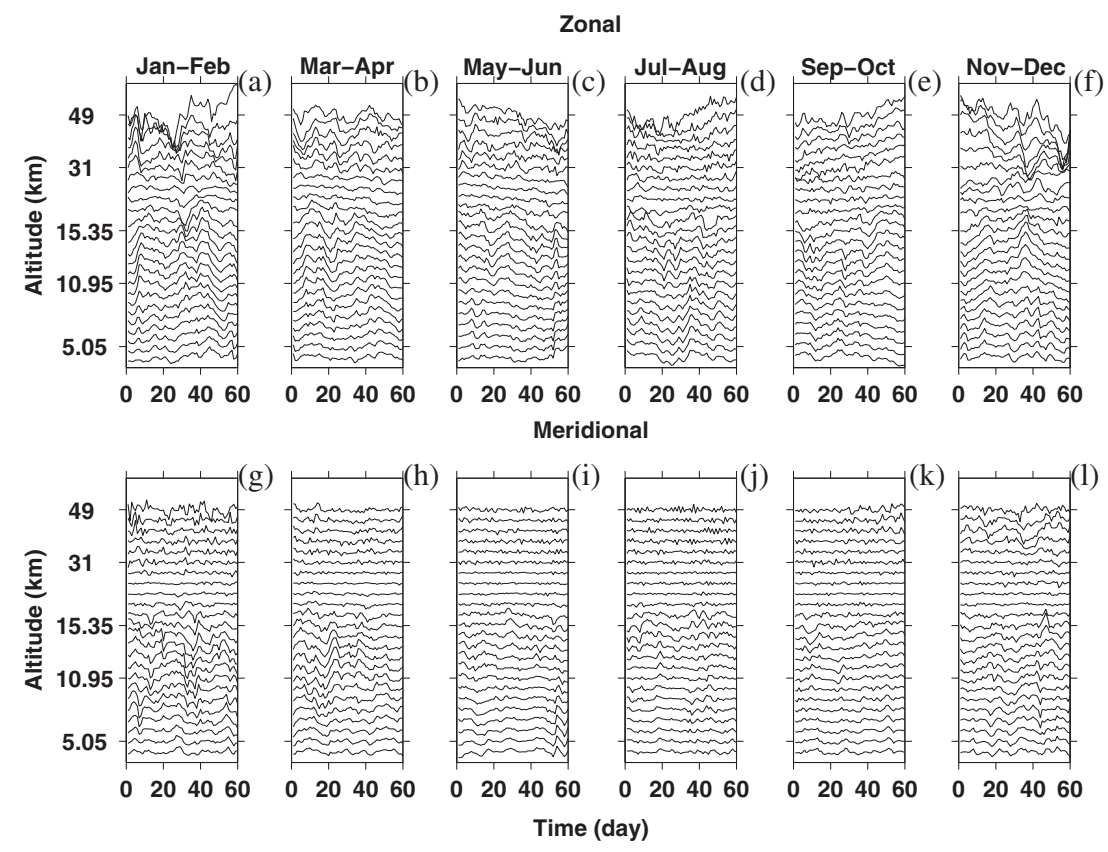

Figure 2. Time series of fluctuations of $(\mathbf{a}-\mathbf{f})$ zonal and $(\mathbf{g}-\mathbf{l})$ meridional winds for ERA data. Wind fluctuations are shifted vertically by $15 \mathrm{~m} / \mathrm{s}$.
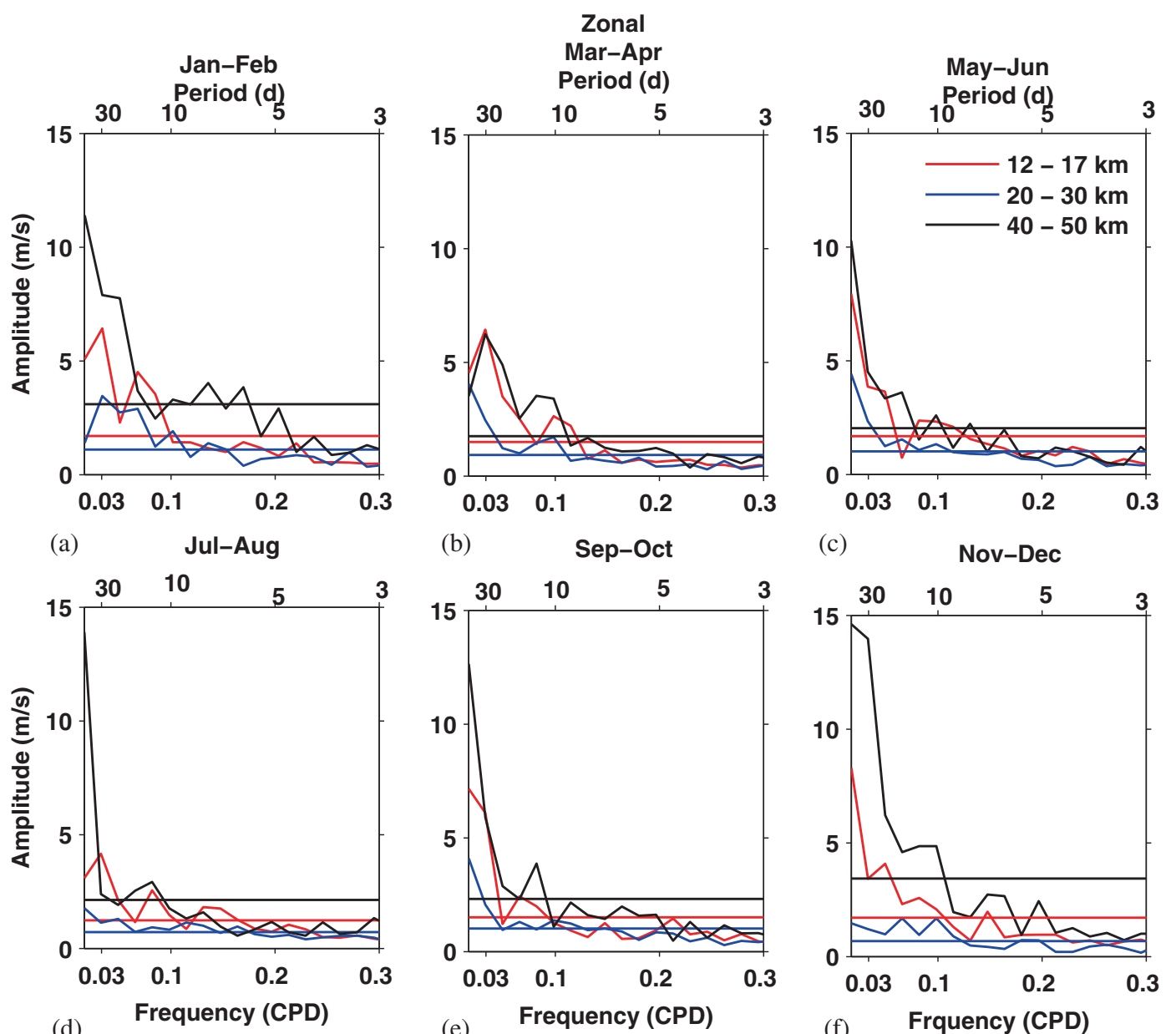

(b)

(c)
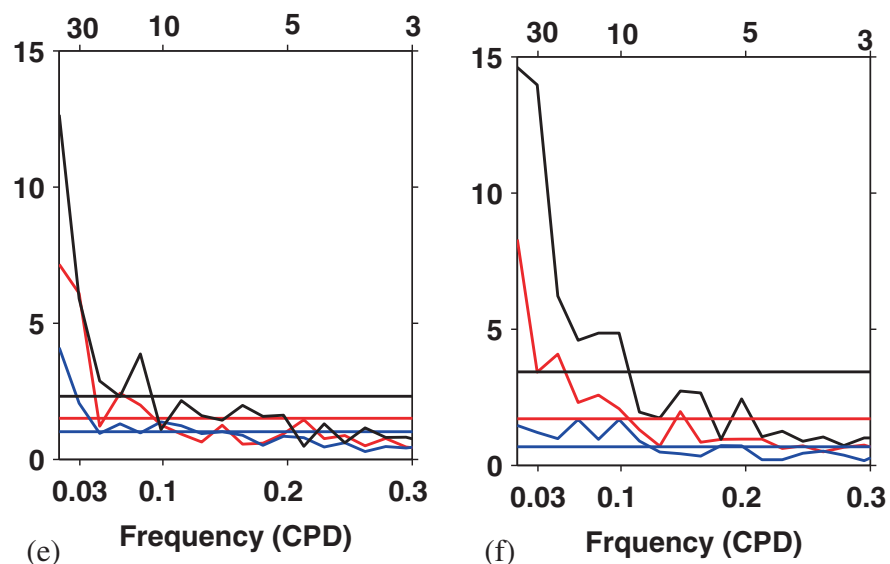

Figure 3. FFT spectra of (a-f) zonal fluctuations of ERA data for different height blocks with $95 \%$ confidence level drawn with the same colours as the spectra. Bottom abscissa: frequency. Top abscissa: period. 
between negative and positive values during June. Winds in other months, i.e., January-March and July-December in this region are northerly. Meridional winds in $40-50 \mathrm{~km}$ range are northwards (southerly) from January to March and October to December. They show an opposite trend in other months. Meridional winds are generally weaker and attain maximum values near $\sim 12-14 \mathrm{~km}$ in tropospheric region. Stratospheric meridional winds are also found to be very weak.

\section{Analysis of ERA data}

\subsection{FFT spectra}

Wind data obtained from ERA-interim for the year 2007 have been split into six slots of two months each (January-February, March-April, May-June, July-August, September-October and NovemberDecember) to have proper comparisons with the results obtained using radar data. Data of each slot has been detrended to get the fluctuating components which are depicted in figure $2(\mathrm{a}-\mathrm{f})$ for zonal and figure $2(\mathrm{~g}-\mathrm{l})$ for meridional winds. Higher wave activity can be seen in the upper troposphere and upper stratosphere whereas less activity is observed between $\sim 20$ and $30 \mathrm{~km}$. Conventional FFT techniques are then applied to the time series of fluctuations of different slots. The spectra are then averaged over three altitude regions: $12-17,20-30$ and 40-50 km which improves their spectral reliability and are illustrated in figures $3(\mathrm{a}-\mathrm{f})$ and $4(\mathrm{a}-\mathrm{f})$ for zonal and meridional cases, respectively. Prominent peaks of 7.5, 10, 15, 20 and $30 \mathrm{~d}$ periodicities are observed in the zonal spectra of three height blocks which are above $95 \%$ confidence levels. The spectral peaks between 20 and $30 \mathrm{~km}$ altitudes are found to be very weak and do not rise above $95 \%$ confidence level. The activity picks up again in the upper stratospheric region above $35 \mathrm{~km}$. The waves are found to be strong during the months between January-April and during November-December. Wave activity in the upper tropospheric region is observed all through the year. Shorter periodicities like 7-10 d periods are found to be prominent in July-August when local convection is high and tropical easterly jet is present. Meridional spectra
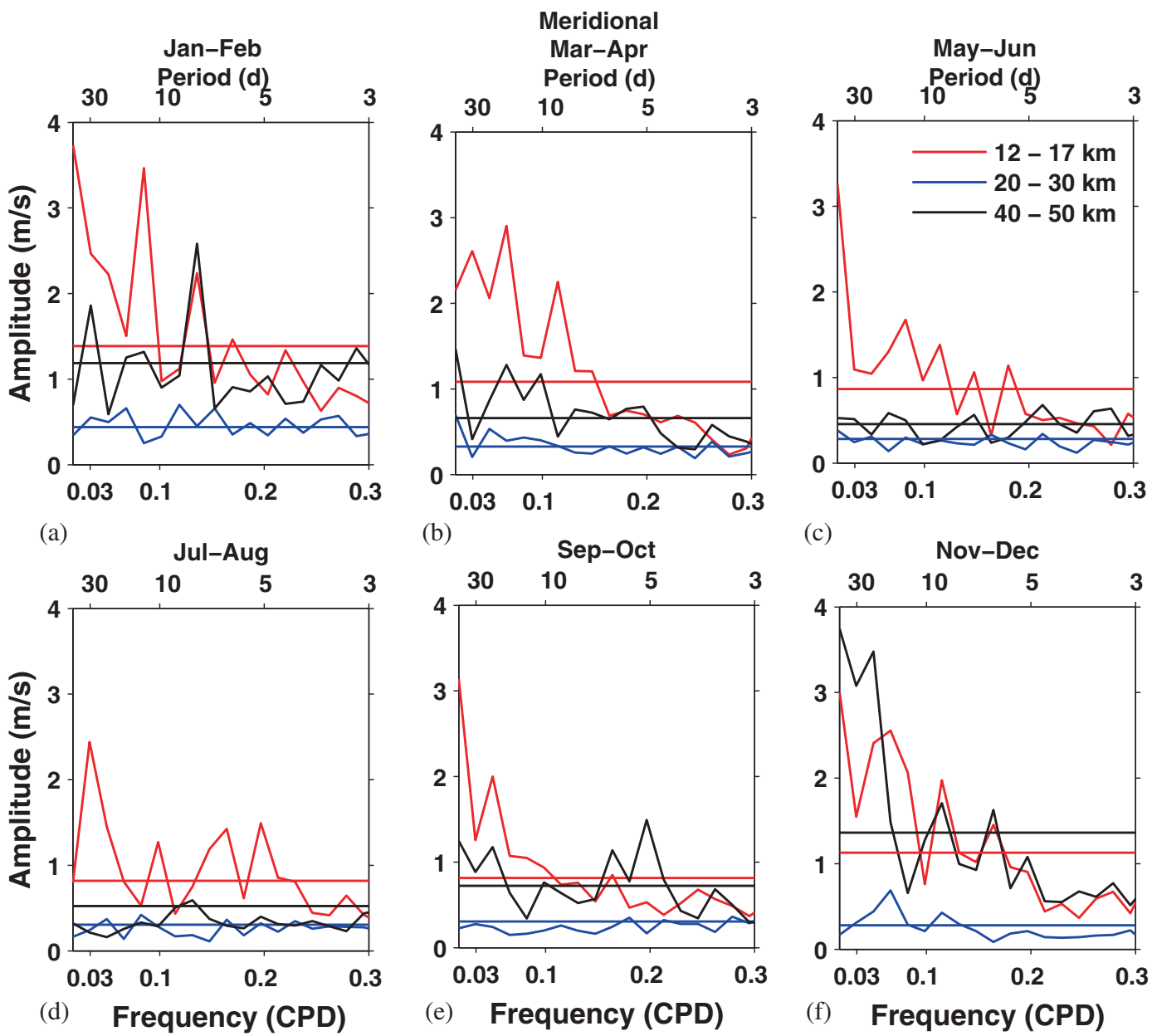

(b)

(c)

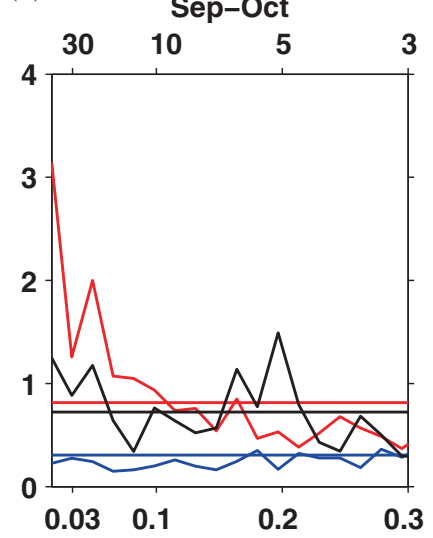

(e) Frequency (CPD)

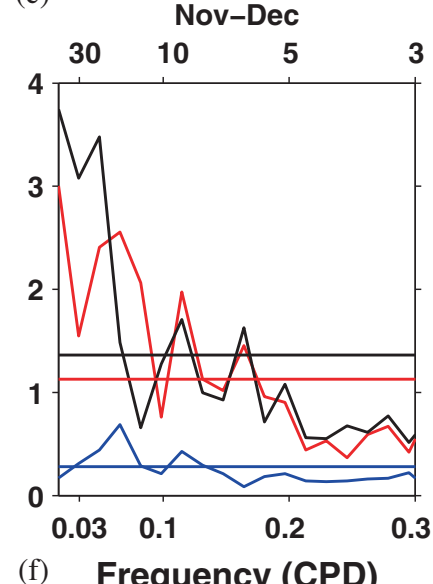

Figure 4. Same as figure 3, but for meridional case. 
show prominent oscillations of similar periods with similar height variations but with less amplitudes.

\subsection{Amplitude-height profiles}

The amplitude-height profiles of the six slots of ERA 2007 wind data are illustrated in figure 5(a-f) for zonal and figure $5(\mathrm{~g}-\mathrm{l})$ for meridional components. The wave amplitudes in three period bands 7-10, 12-15 and 20-30 d show almost similar characteristics. High activities are observed in the troposphere below the tropopause and above $\sim 40$ $\mathrm{km}$ in the stratosphere. The maximum amplitudes obtained below the tropopause and in the upper stratosphere are $\sim 5 \mathrm{~m} / \mathrm{s}$ at $\sim 14 \mathrm{~km}$ and $\sim 8.5 \mathrm{~m} / \mathrm{s}$ near $44 \mathrm{~km}$. Amplitudes are observed to be very less in the $20-30 \mathrm{~km}$ altitude region. Height resolution of ERA data becomes very poor above $\sim 30 \mathrm{~km}$ and hence the results obtained in this region using this data should be accepted with caution. Raghava Rao et al. (1990) used high altitude balloon and rocket data of winds to find the characteristics of 23-60 d oscillations over Sriharikota $\left(13.7^{\circ} \mathrm{N}, 80.2^{\circ} \mathrm{E}\right)$, a tropical station quite close to Gadanki. Their report agrees quite well with the present study but with larger wave amplitudes since they used real measurements. Krishna
Murthy et al. (2002) detected Kelvin waves in the temperature data over Gadanki with periods ranging between $\sim 5$ and $15 \mathrm{~d}$. The oscillation showed maximum amplitudes near 22 and $48 \mathrm{~km}$. Dhaka et al. (1995) analyzed balloon and rocket wind data measured from Trivandrum $\left(8.5^{\circ} \mathrm{N}, 77^{\circ} \mathrm{E}\right)$, Minicoy $\left(8.3^{\circ} \mathrm{N}, 73^{\circ} \mathrm{E}\right)$ and Port Blair $\left(11.7^{\circ} \mathrm{N}\right.$, $92.7^{\circ} \mathrm{E}$ ) and reported significant oscillations below the tropopause centered on periods of around 20, 7 and $4-5 \mathrm{~d}$. The oscillations were found to be very weak near $22 \mathrm{~km}$ and picked up again near $30 \mathrm{~km}$.

\subsection{Generation and propagation of the waves}

The equatorial waves are supposed to be generated in the troposphere by mechanisms like convection, wind shear, etc. Deep convection prevails during Asian Summer Monsoon (ASM) and during northeast (NE) monsoon over Gadanki. Lower values of outgoing long wave radiation (OLR) signifies deep convection in the tropical region and gives rise to waves of different frequencies. Temporal variability of the wave activity can be investigated by forming wavelet spectra of continuous data. We have conducted wavelet analyses of wind data for three altitude blocks as mentioned earlier in section 4.1 and also of OLR daily data of 2007 with a view to

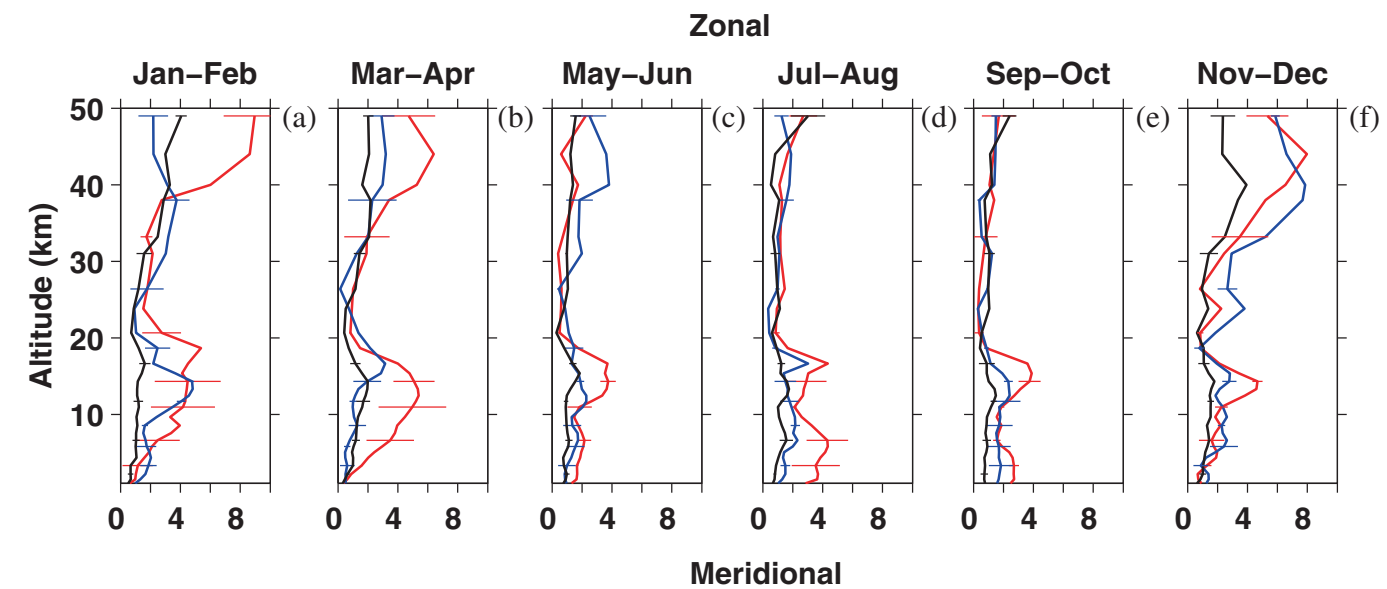

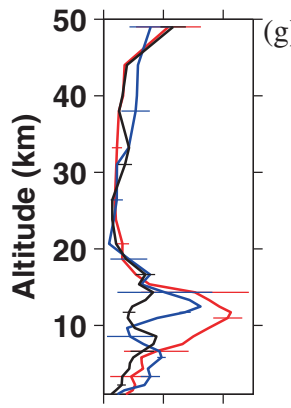

024
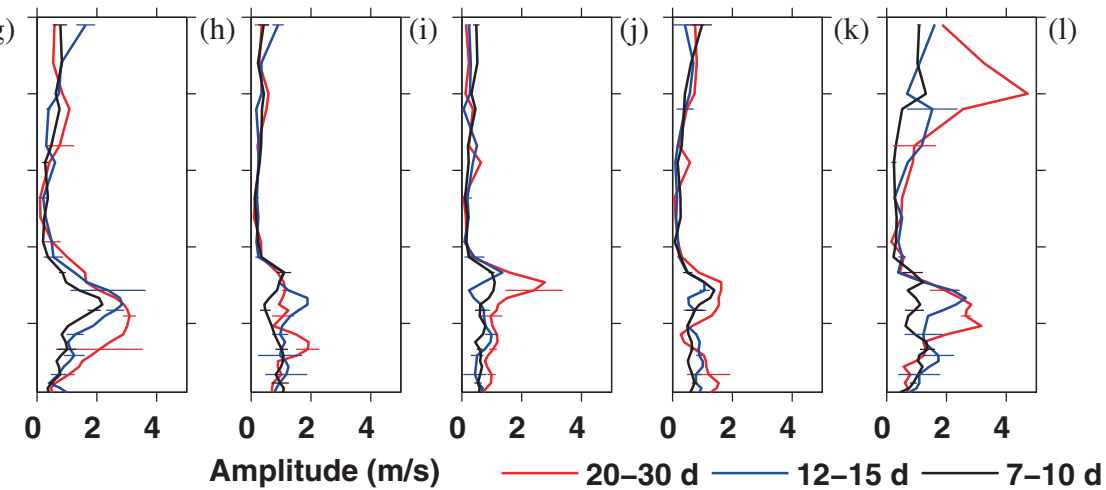

Figure 5. Height profiles of $(\mathbf{a}-\mathbf{f})$ zonal and $(\mathbf{g}-\mathbf{l})$ meridional amplitudes of different periods with standard deviations at a few heights with corresponding colours. 
locating the source of the oscillations. The detrended fluctuations have been subjected to wavelet analysis using Morlet wavelet. The spectra obtained using zonal and meridional winds and corresponding OLR values are depicted in figure $6(\mathrm{a}-\mathrm{h})$. A broad range of periods between 7 and $30 \mathrm{~d}$ can be observed within the cones of influence which are considered to be significant. November-December of 2006 and JanuaryFebruary of 2008 data have been included for

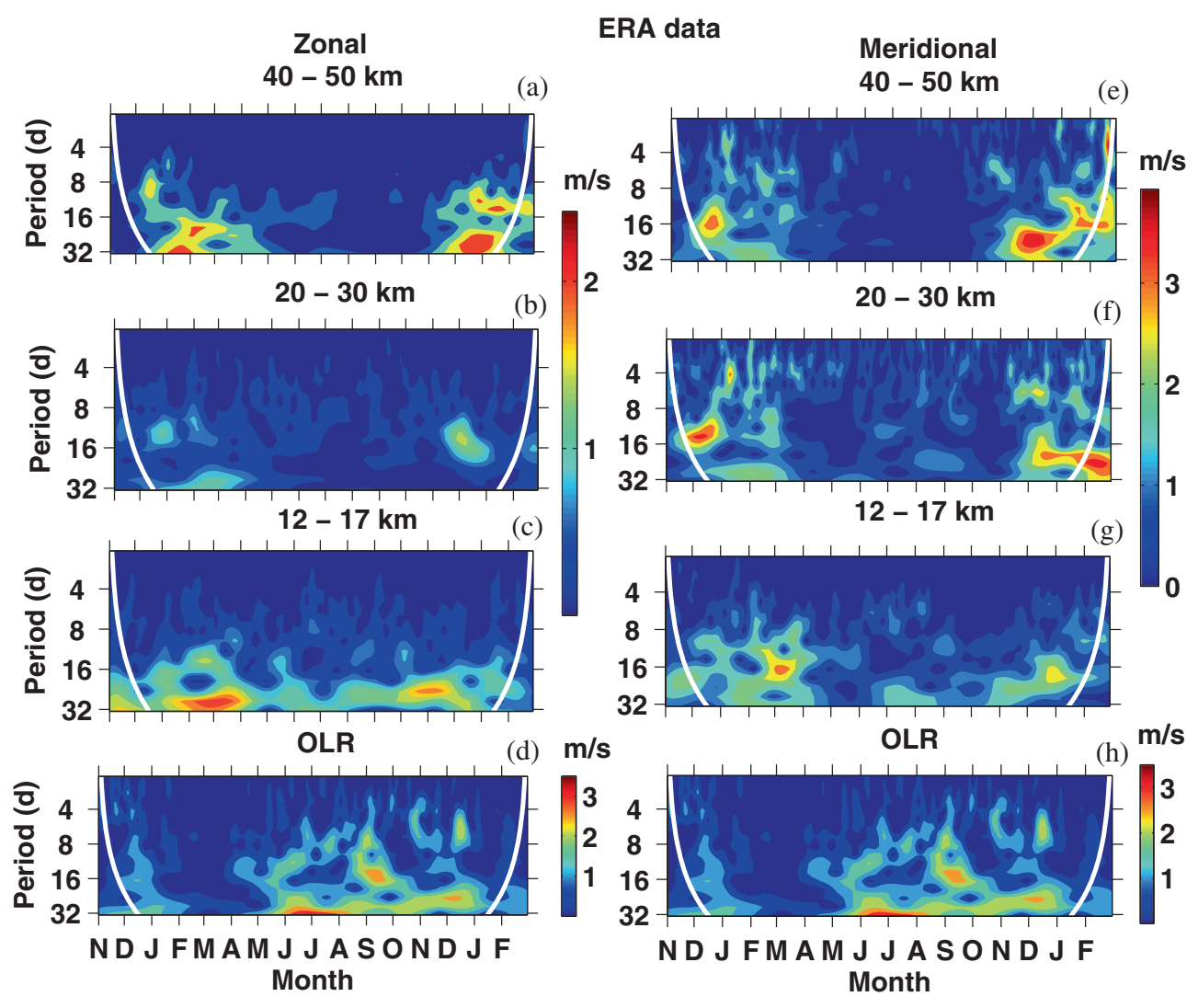

Figure 6. Wavelet transform spectra of $(\mathbf{a}-\mathbf{c})$ zonal and $(\mathbf{e}-\mathbf{g})$ meridional winds for different altitude blocks. Wavelet spectra of OLR data are shown in last panels ( $\mathbf{d}$ and $\mathbf{h})$.

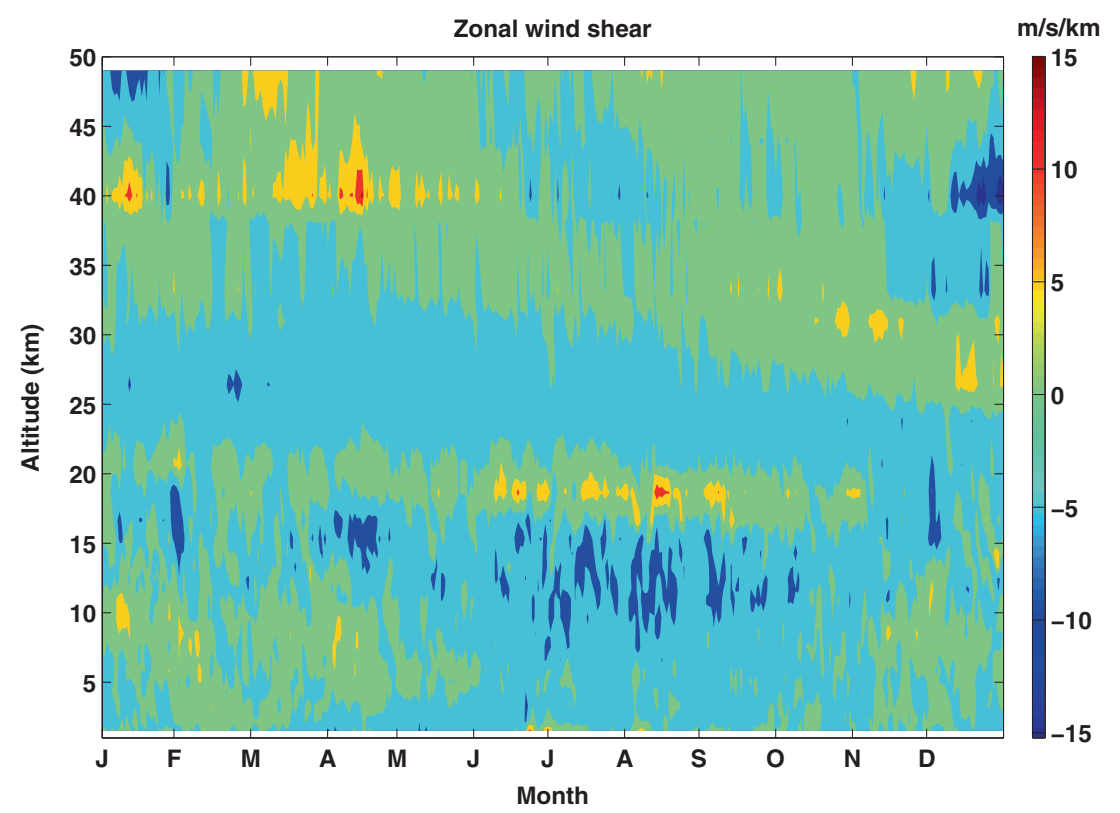

Figure 7. Contour of zonal wind shear (ERA-data). 
wavelet analysis to get a clear picture of the wave activities during 2007 which could lie within the cones. It can be seen from figure $6(\mathrm{~d}$ and $\mathrm{h})$ that the OLR spectra show generation of waves of periods between 8 and $32 \mathrm{~d}$ during the months of May to December, i.e., during ASM and NE monsoon when convection is prevalent over the site. The correlation coefficient between OLR amplitudes and zonal wave amplitudes of 20-30 d waves in the troposphere $(12-17 \mathrm{~km})$ during the convective season (May-December) is found to be very high (0.71) with $95 \%$ confidence level. This shows that a large part of this long period waves are generated by convection in the troposphere. Waves between 1215 and $7-10 \mathrm{~d}$ periods also show positive correlation with OLR amplitudes and are 0.25 and 0.1 , respectively. Meridional amplitudes are weak and the corresponding correlation coefficients are also not significant.

Waves are also produced due to wind shear in the troposphere. The correlation coefficients obtained between zonal wind shear and wave amplitudes of 20-30 and 12-15 d waves are 0.47 and 0.45 in the troposphere between 12 and $17 \mathrm{~km}$ during January to April. The coefficients are found to be less between May and December for 20-30 and $12-15 \mathrm{~d}$ periodicities and are 0.27 and 0.25 respectively. Meridional wave amplitudes do not show appreciable correlations and might be generated due to non-linear wave CISK (Itoh and Ghil 1988 and the references therein). It appears that major reasons of generation of these zonal long period Kelvin waves are due to wind shear during January-April and due to convection during MayDecember. Wind shear is also supposed to have a pronounced effect on filtering of upward propagating waves. Raghava Rao et al. (1990) reported that waves get impeded in the negative wind shear region. The contour of wind shear in the present study, as illustrated in figure 7 shows large negative zonal wind shear below the tropopause between June and October which inhibits these waves to propagate upwards. Mild positive wind shear is observed between January-April and NovemberDecember below the tropopause which allows the waves to travel partially to the lower stratosphere. The region between 20 and $30 \mathrm{~km}$ shows predominantly negative wind shear with corresponding lower wave activities. The wind shear changes its sign above $\sim 35 \mathrm{~km}$ and a spurt of wave activity is demonstrated in the upper stratospheric region. The meridional shear is observed to change sign frequently in the same altitude region (figure not shown).

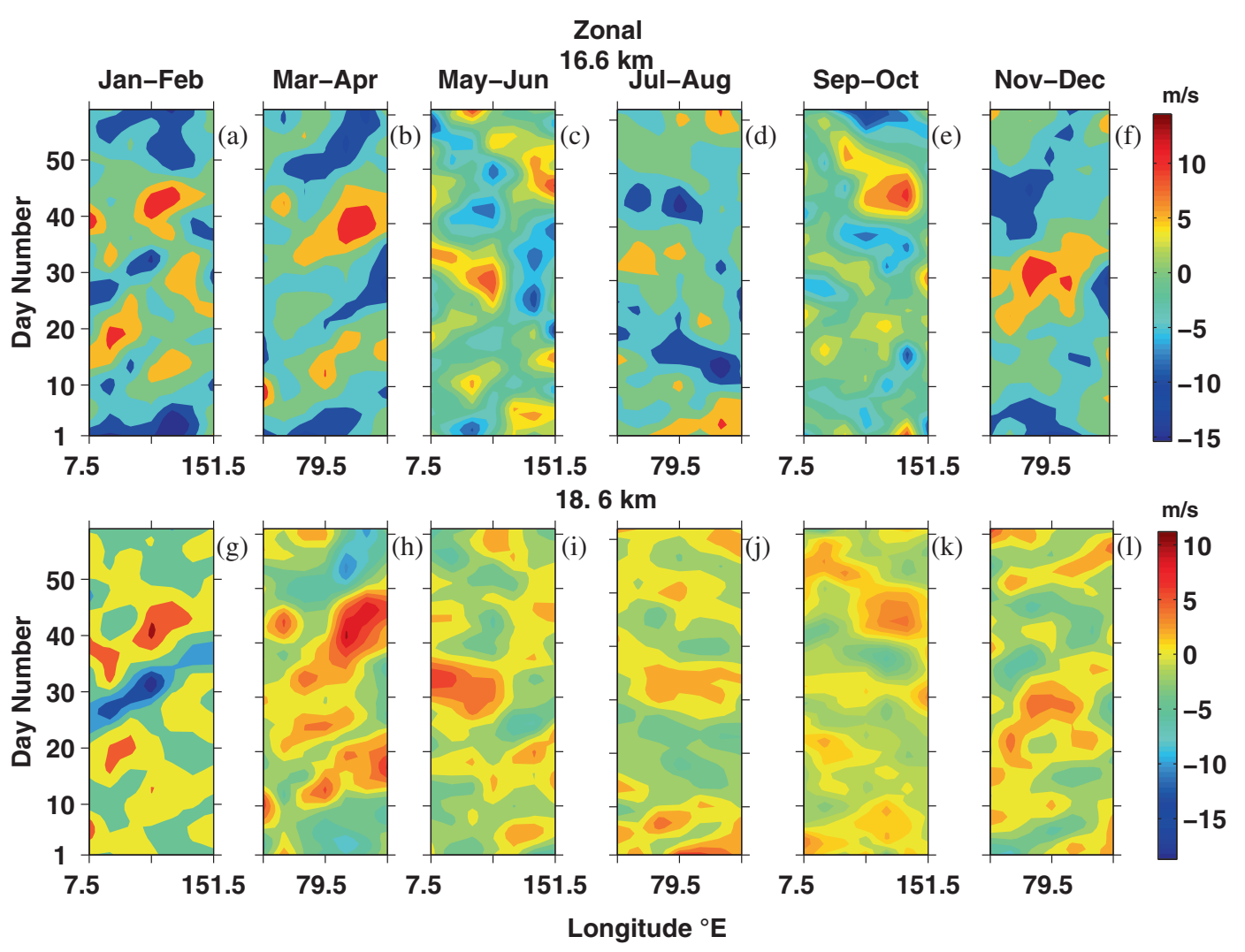

Figure 8. Upper panel: Longitude time contours of zonal fluctuations over $7.5^{\circ}-151.5^{\circ} \mathrm{E}$ during (a) January-February, (b) March-April, (c) May-June, (d) July-August, (e) September-October, and (f) November-December at $16.6 \mathrm{~km}$. Lower panel: Same as upper panel, but for $18.6 \mathrm{~km}(\mathrm{~g}-\mathbf{l})$. 
Propagation directions of the waves have been estimated by plotting time-longitude sections of filtered (low-pass $14 \mathrm{~d}$ ) wind fluctuation contours at 16.6 and $18.6 \mathrm{~km}$ and are depicted in figure $8(\mathrm{a}-\mathrm{l})$. Clear eastward propagation can be observed in the months of January-April and between November and December. The directions are not clear in other months and some westward propagating waves can be identified particularly in JuneJuly-August. The QBO in the stratosphere at 20 $\mathrm{hPa}$ shows westward propagation almost throughout the year 2007. So the eastward propagating waves during January-April and NovemberDecember might propagate upwards whereas the westward propagating ones are filtered out during other months. The zonal wave numbers of the observed waves have been estimated following the relation

$$
s=\frac{\text { Phase difference }}{\text { Longitudinal difference }} .
$$

It is observed that the Kelvin waves at this site are a mixture of $s=1$ and 2. Since the latitude of this station is $\sim 13.5^{\circ}$, the amplitude of Kelvin wave is not very high. The slow Kelvin waves
(20-30 d) have larger amplitudes in zonal winds $(\sim 7 \mathrm{~m} / \mathrm{s})$ compared to meridional ones $(\sim 3.5 \mathrm{~m} / \mathrm{s})$ in the upper troposphere during January-February (figures 3 and 4). Amplitudes of this oscillation follow the same trend in other months as well. The shorter period $(7-10 \mathrm{~d})$ waves are seen in JulyAugust in tropospheric region and have comparable amplitudes in both the wind components. They can be classified as Mixed Rossby Gravity (MRG) waves. The vertical wavelengths of the waves have been computed using the formula given by Holton et al. (2001)

$$
L_{z}=\frac{2 \pi}{N}\left(\frac{L_{x}}{\tau}-\bar{u}\right)
$$

where $\bar{u}, N, \tau, L_{x}$ and $L_{z}$ are velocity of mean zonal wind, buoyancy frequency, wave period, zonal wavelength and vertical wavelength respectively. The zonal wavelengths $\left(L_{x}\right)$ are taken as $40,200 \mathrm{~km}$ for wave 1 and 20,100 $\mathrm{km}$ for wave 2 (Tsai et al. 2004; Brahmanandam et al. 2010). The vertical wavelengths are found to vary between 5 and $16 \mathrm{~km}$. The vertical wavelengths reported by other workers also fall in the same range.
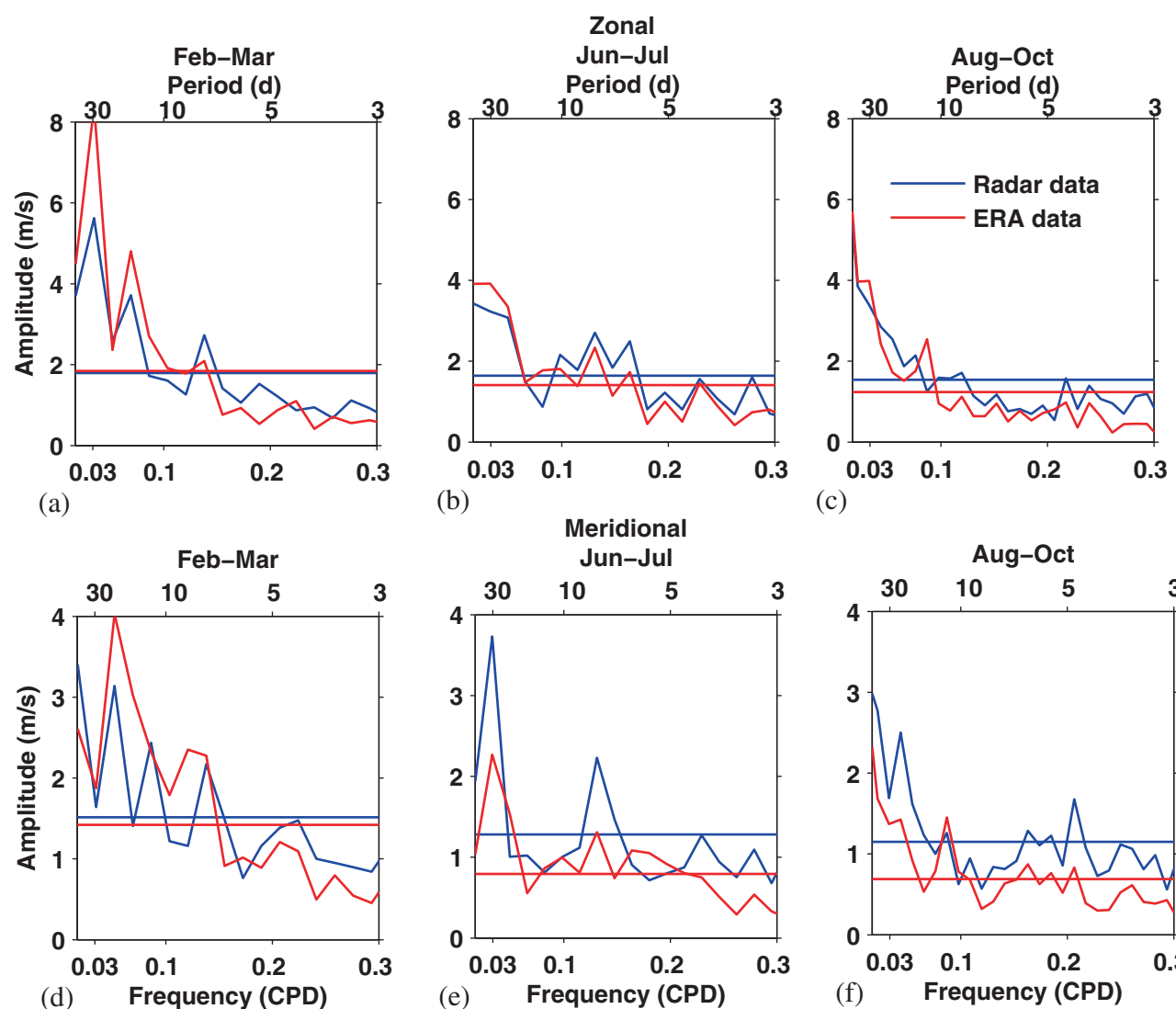

(b)

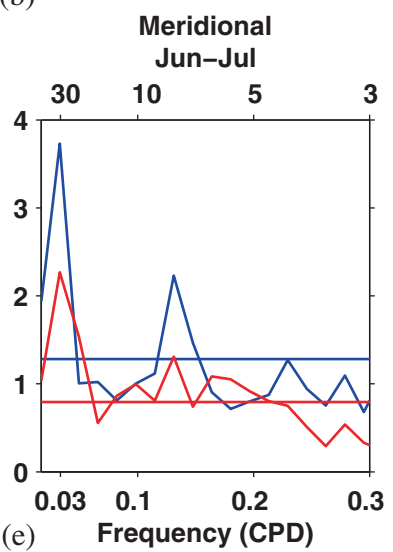

(c)

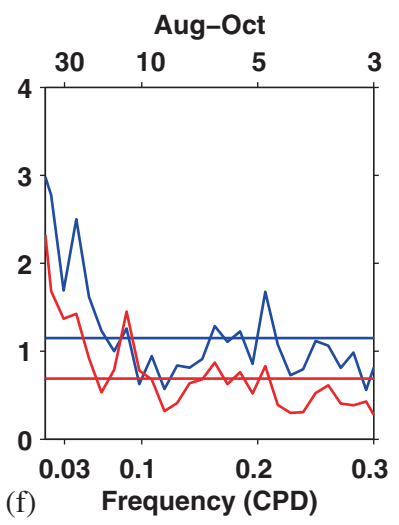

Figure 9. Upper panel: Comparisons of FFT spectra of zonal fluctuations for different months (a-c) averaged over a height block of 12-17 km. Bottom abscissa: frequency. Top abscissa: period. Lower panel: Same as upper panel, but for meridional $(\mathbf{d}-\mathbf{f})$ case. 


\section{Analysis of MST radar data}

Description of the radar and details of the database are given in section 2. The radar winds have been checked for quality by visual inspection. Outliers are removed by discarding values exceeding 1.7 times the standard deviation from 10 days' mean values. The meridional wind data are not found to be of very high quality since north and south beam spectra do not match properly, particularly between 12 and $20 \mathrm{~km}$. Available radar wind data are then divided in three slots: FebruaryMarch, June--July and August-October which are detrended to obtain the fluctuating components.

\subsection{FFT spectra}

FFT analyses have been carried out on the time series of fluctuations obtained using three slots of wind data as mentioned, in a similar manner as described in section 4.1. The spectra obtained using ERA and radar data of same slots have been compared in figure 9. The wave periods and amplitudes are found to match quite well in the zonal spectra whereas the agreements are not so good in meridional components which could be attributed to the poor quality of meridional wind data. The longer period wave amplitudes might also be affected due to interpolation.

\section{Summary}

Observations of Kelvin and MRG waves were first reported by Wallace and Kousky in 1968 and Yanai and Maruyama in 1966 respectively. There have been numerous studies since that time to identify and characterize these equatorial waves using radiosonde, radar and satellite measurements. The present work utilizes ERA-interim daily wind data of the year 2007 to study some characteristics of equatorial waves over the tropical latitude $13.5^{\circ} \mathrm{N}$ where Gadanki MST radar is located. Available wind data obtained from the radar during the same year have been analyzed to compare and find out what portion of the spectra is seen by the radar. Equatorial waves in the period range between 7-10, 12-15 and 20-30 d have been identified in the FFT spectra. The wave activity is seen almost throughout the year in the upper tropospheric region between 12 and $17 \mathrm{~km}$ with varied intensity. Shorter period waves are more frequently seen between June and August months. The waves are found to be partially generated in the troposphere by wind shear and convection. The cross-correlation coefficients observed between wave amplitudes and wind shear during JanuaryApril is $\sim 0.5$ for longer period waves. Wavelet analysis of winds and OLR data shows similar periods and the longer period waves are found to be highly correlated (0.71) with each other in the upper troposphere. The waves are found to be almost evanescent in the lower stratosphere between 20 and $30 \mathrm{~km}$ which is a mild negative wind shear zone. The amplitudes pick up again in the upper stratosphere above $30 \mathrm{~km}$. These waves show a strong seasonal variation with maxima in winter months and minima in summer months. Time-longitude sections of wind fluctuation contours confirm eastward propagation of the waves during the active months. Propagation directions during summer months are not very clear but show more westward. The phase of QBO is mainly westwards throughout 2007 which inhibits the waves to propagate upwards particularly during MayOctober. Background wind also plays a vital role in the propagation of the waves. The wave amplitudes are impeded in the negative shear zone in the strong negative wind shear layer between 18 and 20 $\mathrm{km}$ during June-October. The wave propagation gets inhibited to travel above $20 \mathrm{~km}$ by a strong negative wind shear layer below the tropopause during May-October.

Equatorial waves at this station appear to be a mixture of slow Kelvin waves and Mixed Rossby Gravity (MRG) waves with $s=1$ and 2. The dynamics observed by ERA-interim winds and radar measured winds has been investigated by spectral analysis which show similar wave periods and amplitudes. Reliability of the results obtained using ERA-interim data in the upper stratosphere is less due to its poor height resolution. Future work will concentrate on the latitudinal variation of these global oscillations.

\section{Acknowledgements}

Authors wish to express their gratitude to the Director, National Atmospheric Research Laboratory (NARL), Gadanki for providing data for the analysis. Two of the authors (Salauddin Mohammad and P Vinay Kumar) are thankful for the research fellowships offered by Indian Space Research Organization (ISRO) under its CAWSES programme. The authors would also like to thank the college management for their kind support. The authors thank the anonymous reviewer for his constructive comments which substantially improved the quality of the paper.

\section{References}

Alexander S P, Tsuda T, Kawatani Y and Takahashi M 2008 Global distribution of atmospheric waves in the equatorial upper troposphere and lower stratosphere: COSMIC 
observations of wave mean flow interactions; J. Geophys. Res. 113 D24115, doi: 10.1029/2008JD010039.

Andrews D G, Holton J R and Leovy C B 1987 Middle Atmosphere Dynamics; Academic Press, San Diego, California, 489p.

Brahmanandam P S, Chu Yen-Hsyang and Liu Jimmy 2010 Observations of equatorial Kelvin wave modes in FORMOSAT - 3/COSMIC GPS RO temperature profiles; Terr. Atmos. Ocean Sci. 21(5) 829-840.

Canziani P O and Holton J R 1998 Kelvin waves and the quasi-biennial oscillation: An observational analysis; J. Geophys. Res. 103 31,509-31,521.

Dhaka S K, Kumar A and Nagpal O P 1993 Some studies of tropical/equatorial waves over Indian tropical middle atmosphere: Results of tropical wave campaign; Meteorol. Atmos. Phys. 51 25-39.

Dhaka S K, Krishna Murthy B V, Nagpal O P, Raghava Rao R, Sasi M N and Sundaresan S 1995 A study of equatorial waves in the Indian zone; J. Atmos. Sol. Terr. Phys. 57(11) 1189-1202.

Dutta G, Bapiraju B, Balasubrahmanyam P, Aleem Siddiqui M A and Aleem Basha H 2002 Seasonal variation of solar tides in the troposphere and lower stratosphere over Gadanki: Comparisons with the global scale wave model; Radio Sci. 37(2), doi: 10.1029/2000RS002571.

Ern M, Preusse P, Krebsbach M, Mlynczak M G and Russell III J M 2008 Equatorial wave analysis from SABER and ECMWF temperatures; Atmos. Chem. Phys. 8 845869.

Flannaghan T J and Fueglistaler S 2011 Kelvin waves and shear-flow turbulent mixing in the TTL in (re-) analysis data; Geophys. Res. Lett. 38 L02801, doi: 10.1029/2010GL045524.

Fujiwara M, Kita K and Ogawa T 1998 Stratospheretroposphere exchange of ozone associated with the equatorial Kelvin wave as observed with ozonsondes and rawinsondes; J. Geophys. Res. 103 19,17319,182 .

Fujiwara M, Hasebe F, Shiotani M, Nishi N, Vomel H and Oltmans S J 2001 Water vapor control at the tropopause by equatorial Kelvin waves observed over the Galapagos; Geophys. Res. Lett. 28 3143-3146.

Holton J R and Lindzen R S 1972 An updated theory for the quasi-biennial oscillation; J. Atmos. Sci. 29 10761080 .

Holton J R, Alexander M J and Boehm M T 2001 Evidence for short vertical wavelength Kelvin waves in the Department of Energy-Atmosphere Radiation Measurement Nauru99 radiosonde data; J. Geophys. Res. 106(D17) 20,125-20,130.

Huang F T, Mayr H G, Reber C A, Russell J M, Mylnczak $\mathrm{M}$ and Mengel J 2006 Zonal-mean temperature variations inferred from SABER measurements on TIMED, compared with UARS observations; J. Geophys. Res. 111 A10S07, doi: 10.1029/2005JA011427.

Huang F T, McPeters R D, Bhartia P K, Mayr H G, Frith S M, Russell III J M and Mlynczak M G 2010 Temperature diurnal variations (migrating tides) in the stratosphere and lower mesosphere based on measurements from SABER on TIMED; J. Geophys. Res. 115 D16121, doi: 10.1029/2009JD013698.

Itoh $\mathrm{H}$ and Ghil M 1988 The generation mechanism of mixed Rossby-Gravity waves in the equatorial troposphere; J. Atmos. Sci. 45 585-604.

Krishna Murthy B V, Satheesan K, Parameswaran K, Sasi M N, Geetha Ramkumar, Bhavanikumar Y, Raghunath K and Krishnaiah M 2002 Equatorial waves in temperature in the altitude range 4 to $70 \mathrm{~km}$; Quart. J. Roy. Meteorol. Soc. 128 819-837.
Liebmann B and Hendon H H 1990 Synoptic-scale disturbances near equator; J. Atmos. Sci. 47 1463-1479.

Mote P W, Dunkerton T J and Wu D 2002 Kelvin waves in stratospheric temperature observed by the Microwave Limb Sounder; J. Geophys. Res. 107(D14) 4218, doi: 10.1029/2001JD001056.

Raghavarao Rao, Suhasini R, Sridharan R, Krishnamurthy B V and Nagpal O P 1990 Vertical structure and characteristics of 23-60 day (zonal) oscillations over the tropical latitudes during the winter months of $1986-$ Results of equatorial wave campaign-II; 99(3) 413423.

Randel W J and Fei Wu 2005 Kelvin wave variability near the equatorial tropopause observed in GPS radio occultation measurements; J. Geophys. Res. 110, doi: 10.1029/2004JD005006.

Rao P B, Jain A R, Kishore P, Balamuralidhar P, Damle S $\mathrm{H}$ and Viswanathan G 1995 Indian MST radar: 1. System description and sample vector wind measurements in ST mode; Radio Sci. 30 1125-1138, doi: 10.1029/95RS00787.

Ratnam M V, Tetzlaff G and Jacobi C 2004 Global and seasonal variations of stratospheric gravity wave activity deduced from the CHAMP/GPS satellite; J. Atmos. Sci. 61 1610-1620.

Ryu J H, Lee S and Son S W 2008 Vertically propagating Kelvin waves and tropical tropopause variability; J. Atmos. Sci. 65 1817-1837.

Salby M L, Hartmann D L, Bailey P L and Gille J C 1984 Evidence for equatorial Kelvin Modes in Nimbus - 7 LIMS; J. Atmos. Sci. 41(2) 220-235.

Sasi M N, Ramkumar G and Deepa V 1998 Non-migrating diurnal tides in the troposphere and lower stratosphere over Gadanki $\left(13.5^{\circ} \mathrm{N}, 79.2^{\circ} \mathrm{E}\right) ;$ J. Geophys. Res. 103 $19,485-19,494$.

Sasi M N, Vijayan L, Deepa V and Krishna Murthy B V 1999 Estimation of equatorial wave momentum fluxes using MST radar winds observed at Gadanki $\left(13.5^{\circ} \mathrm{N}, 79.2^{\circ} \mathrm{E}\right)$; J. Atmos. Sol. Terr. Phys. 61 377-384.

Sasi M N and Deepa V 2001 Seasonal variation of equatorial wave momentum fluxes at Gadanki $\left(13.5^{\circ} \mathrm{N}, 79.2^{\circ} \mathrm{E}\right)$; Ann. Geophys. 19 985-990.

Sato K and Dunkerton T J 1997 Estimates of momentum flux associated with equatorial Kelvin and gravity waves; J. Geophys. Res. 102 26,247-26,261.

Shimizu A and Tsuda T 1997 Characteristics of Kelvin waves and gravity waves observed with radiosondes over Indonesia; J. Geophys. Res. 102 26,159-26,171.

Sridharan S, Tsuda T, Nakamura T, Kozu T, Mori S and Russell J M 2006a Observations of the 7-day Kelvin wave in the tropical atmosphere during the CPEA campaign; J. Meterol. Soc. Japan 84A 259-275.

Sridharan S, Tsuda T, Nakamura T, Vincent R A and Effendy $2006 \mathrm{~b}$ A report on radar observations of 5-8 day waves in the equatorial MLT region; J. Meterol. Soc. Japan 84A 295-304.

Tsai H F, Tsuda T, Hajj G A, Wickert J and Aoyama Y 2004 Equatorial Kelvin waves observed with GPS occultation measurements (CHAMP and SAC-C); J. Meteorol. Soc. Japan 82(1B) 397-406.

Tsuda T, Murayama Y, Wiryosumreto H, Harijono S W B and Kato S 1994 Radiosonde observations of equatorial atmospheric dynamics over Indonesia: 1. Equatorial waves and diurnal tides; J. Geophys. Res. 99 10,49110,505 .

Vincent R A, Kovalam S, Fritts D C and Isler J R 1998 Long-term MF radar observations of solar tides in the low-latitude mesosphere: Interannual variability and comparisons with the GSWM; J. Geophys. Res. 103(D8) 8667-8683. 
Wallace J M and Kousky V E 1968 Observational evidence of Kelvin waves in the tropical stratosphere; J. Atmos. Sci. 25 900-907.

Wu D L, McLandress C, Read W G, Waters J W and Froidevaux L 1998 Equatorial diurnal variations observed in UARS microwave limb sounder temperature during 1991-1994 and simulated by the Canadian middle atmosphere model; J. Geophys. Res. 103 89098917.

Yanai M and Maruyama T 1966 Stratospheric wave disturbance propagating over equatorial Pacific; J. Meteorol. Soc. Japan 44 291-294.

MS received 28 April 2014; revised 19 January 2015; accepted 19 January 2015 